\title{
Immunobiology of pleural inflammation: potential implications for pathogenesis, diagnosis and therapy
}

\author{
C. Kroegel*, V.B. Antony**
}

Immunobiology of pleural inflammation: potential implications for pathogenesis, diagnosis and therapy. C. Kroegel, V.B. Antony. (C)ERS Journals Ltd 1997.

ABSTRACT: Although infectious, inflammatory and neoplastic diseases frequently involve the pleural space and walls, little is known about the immunological and molecular mechanisms underlying pleural disorders. This article provides an overview of recent insights into immunobiological processes likely to play a role in the pathogenesis of pleural disorders.

Pleural involvement in certain diseases is associated with the infiltration of a number of different types of immune cells, such as neutrophils, eosinophils or lymphocytes, in various proportions depending on both the course and the aetiology of the underlying disease. In addition to infiltrating cells, mesothelial cells have been demonstrated to actively participate in pleural inflammation via release of various mediators and proteins, including platelet-derived growth factor (PDGF), interleukin-8, monocyte chemotactic peptide (MCP-1), nitric oxide (NO), collagen, antioxidant enzymes and the plasminogen activation inhibitor (PAI). Furthermore, several inflammatory mediators have been detected at increased concentrations within pleural effusions, including lipid mediators, cytokines and proteins (adenosine deaminase, lysosyme, esinophil-derived cationic proteins, and products of the coagulation cascade). The presence of these mediators underline the concept of pleural inflammation, and certain cytokines seem to characterize a specific aetiology of pleurisy.

The understanding of these processes and the sequence of events leading to pleural loculation, pleural adhesion or repair are likely to provide the basis for early therapeutic intervention and reduce pleural-associated morbidity.

Eur Respir J 1997; 10: 2411-2418.
*Pneumology, Dept IV, Medical Clinics, Friedrich Schiller University, Jena, Germany. **Indiana University School of Medicine, Richard Roudebush VA Medical Center, Indianapolis, IN 46202, USA

Correspondence: C. Kroegel

Pneumology, Dept IV

Medical Clinics

Friedrich Schiller University

Erlanger Allee 101

D-07747 Jena

Germany

Keywords: Mechanism of pleurodesis pathogenesis

pleural cell infiltration

pleural disease

pleural fluid cytokines

pleural immune response

Received: April 21997

Accepted after revision July 311997
Since the serous pleural layers are highly permeable and closely related to local microcirculation, the contents of the pleural space are likely to reflect an ongoing immunological or inflammatory process. However, amid general agreement that infectious, inflammatory and neoplastic diseases frequently involve the pleural space, until very recently little research effort has been directed to the immunological and molecular mechanisms underlying pleural disorders. This article, therefore, presents a discussion of the processes likely to occur in diseases related to the pleura. In addition, the review considers how a better understanding of these mechanisms will help elucidate the pathogenesis of pleural inflammation and suggests potential future strategies for the treatment and management of pleural disease.

\section{Aetiology of pleural immune activation}

The pleural cavity may be directly or indirectly involved in disease processes of the adjacent lung or vascu- lar tissue. This is likely to be the case when inflammatory processes occur in the most peripheral alveolar units, such as in pneumonia. Here, increased vascular permeability of local capillaries may lead to increased fluid accumulation not only in the lung, but also in the pleural space. In addition, locally released inflammatory mediators may diffuse into the subpleural or pleural tissue, resulting in a local activation of constitutive cells, including mesothelial cells. As a consequence, directed migration of circulating inflammatory cells into the pleural cavity may cause an increase in pleural cell numbers.

In other conditions, such as mesothelioma or other asbestos-related disorders, the pleural cavity and the mesothelial cells may be affected primarily, and may determine the clinical picture of the disease. The aetiological agent or malignant cell penetrates into, or directly descends from, the pleural layer resulting in a direct activation of constitutive immune cells. This may occur either as a result of cellular immune mechanisms

Previous articles in this series: No. 1: G. Miserocchi. Physiology and pathophysiology of pleural fluid turnover. Eur Respir J 1997; 10: 219-225. No. 2: R.W. Light. Diagnostic principles in pleural disease. Eur Respir J 1997; 10: 476-481. No. 3: G.T. Kinasewitz. Transudative effusions. Eur Respir J 1997; 10: 714-718. No. 4: J. Ferrer. Pleural tuberculosis. Eur Respir J 1997; 10: 942-947. No. 5: H. Hamm, R.W. Light. Parapneumonic effusion and empyema. Eur Respir J 1997; 10: 1150-1156. No. 6: G. Hillerdal. Chylothorax and pseudochylothorax. Eur Respir J 1997; 10: 1157-1162. No. 7: F.M.N.H. Schramel, P.E. Postmus, R.G.J.R.A. Vanderschueren. Current aspects of spontaneous pneumothorax. Eur Respir J 1997; 10: 1372-1379. No. 8: F. Rodriguez-Panadero, V.B. Antony. Pleurodesis: state of the art. Eur Respir J 1997; 10: 1648-1654. No. 9: S.A. Sahn. Pleural diseases related to metastatic malignancies. Eur Respir J 1997; 10: 1907-1913. 
Table 1. - Basic causes, proinflammatory stimuli and pathology of pleural inflammation

\begin{tabular}{|c|c|c|c|}
\hline Aetiology & Inflammatory agents & Pathology & Disease \\
\hline Bacterial invasion & $\begin{array}{l}\text { LPS, other bacterial } \\
\text { pathogens }\end{array}$ & $\begin{array}{l}\text { Neutrophil infiltration } \\
\text { fibrin deposition fibrosis, }\end{array}$ & $\begin{array}{l}\text { Parapneumonic pleurisy, } \\
\text { empyema }\end{array}$ \\
\hline Immunological disorder & $\begin{array}{l}\text { Immune complexes, } \\
\text { activated lymphocytes }\end{array}$ & $\begin{array}{l}\text { Vasculitis, immune complex } \\
\text { deposition, inflammatory } \\
\text { cell infiltration }\end{array}$ & $\begin{array}{l}\text { Lupus erythematodes, } \\
\text { rheumatoid pleurisy }\end{array}$ \\
\hline $\begin{array}{l}\text { Primary and secondary } \\
\text { pleural cancer }\end{array}$ & $\begin{array}{l}\text { Tumour-associated antigens } \\
\text { anti-tumour immune } \\
\text { response }\end{array}$ & $\begin{array}{l}\text { Tumour cell infiltration } \\
\text { and growth }\end{array}$ & $\begin{array}{l}\text { Malignant mesothelioma, } \\
\text { bronchogenic carcinoma } \\
\text { metastatic cancer }\end{array}$ \\
\hline $\begin{array}{l}\text { Fibre-associated } \\
\text { nonmalignant disease }\end{array}$ & Fibres & $\begin{array}{l}\text { Benign effusion, pleural } \\
\text { fibrosis, plaques, } \\
\text { neutrophil accumulation }\end{array}$ & Asbestos-related pleurisy \\
\hline
\end{tabular}

LPS: lipopolysaccaride.

expressed locally or due to the participation of pleural capillaries and subserosal regions in the course of a systemic immune disease, such as seen in immune complex vasculitis. The principle aetiology for direct participation of the pleural space and membranes in immune reactions is delineated in table 1 .

\section{Pleural cells}

In healthy conditions, the pleural fluid contains only a small number of cells, rarely exceeding 100 cells $\mu \mathrm{L}^{-1}$ and consisting mainly of lymphocytes [1]. However, pleural involvement in certain diseases is associated with the infiltration of immune cells such as neutrophils, eosinophils, lymphocytes or accessory cells in various proportions. Although the predominance of an inflammatory cell type within the pleural space is only of limited diagnostic value, it may reflect the immunological process and allow a narrowing of the differential diagnosis.

\section{Neutrophils}

An influx of neutrophils into the pleural space occurs in the course of various pleural diseases. Large numbers of neutrophils are usually detected in the course of complicated parapneumonic effusion or empyema, pancreatitis, subphrenic abscesses and early tuberculosis [1]. Following injection of intrapleural sclerosing agents, such as tetracycline, streptococcal OK-432, or Corynebacterium parvum increased numbers have been observed $[2,3]$. The diagnostic significance of neutrophils is limited, but detection of a significant number may indicate an early phase of the inflammatory process.

Neutrophils may be recruited into the pleural cavity by means of the chemotactic cytokine interleukin-8 (IL8) released by pleural mesothelial cells in response to bacterial endotoxin and cytokines [4], asbestos [5], or instilled agents [6]. In addition to IL-8, a recent study showed that $\mathrm{C} 5 \mathrm{a}$ may also contribute significantly to pleural accumulation of neutrophils following instillation of the streptococcal preparation OK-432 [3]. Though the consequences of neutrophil pleural infiltration are not known, it may be speculated that these cells secrete toxic proteins and oxygen radicals which may elicit mesothelial damage and, consequently, induce fibrosis.

\section{Eosinophils}

Pleural eosinophilia is defined as the presence of $10 \%$ or more eosinophils among the leucocytes in the pleural fluid. The incidence of eosinophilic pleural effusion is not known with certainty, but various studies estimate an incidence ranging 1-15\% [7, 8]. Eosinophils are usually found in pleural effusions associated with pneumothorax, asbestosis, pulmonary infarction, sarcoidosis and collagen vascular disease [1]. In addition, eosinophils often occur in pleural effusion due to drug reactions or parasitic infections, as well as fungal disease $[10,11]$. However, pleural fluid eosinophilia is most commonly associated with the presence of air or blood in the pleural space [12]. In contrast, eosinophilia is rare in tuberculous pleurisy and neoplastic disorders [8]. Interleukin 3 (IL-3) and interleukin 5 (IL-5) have been shown to be chemotactic for eosinophils. The significance of eosinophils in the pleural space remains unclear.

\section{Lymphocytes}

Pleural infiltration by lymphocytes is often observed in the course of malignant disease or tuberculosis. In this context, the detection of a high percentage of small lymphocytes is of particular diagnostic significance [13]. In addition, infiltrating lymphocytes are predominantly T-cells [14] and are of the CD4+ helper/inducer phenotype [15]. Lymphocytic chemotactic factor (LCF), monocyte chemotactic peptide (MCP-1) and IL- 8 have chemotactic properties for lymphocytes and have been demonstrated to be present in lymphocyte-predominant pleural effusions $[13,14]$. Data on the phenotype of pleural lymphocytes are inconsistent, but suggest an active participation of this cell type in pleural immune reactions. For instance, the proportions of CD3+ and CD4+ lymphocytes obtained from tuberculous effusion were significantly greater than the respective phenotype in blood [16]. The ability of pleural lymphocytes to develop interleukin-2 (IL-2)-activated killer activity was enhanced in cells obtained from cancer patients as compared to those obtained from nonmalignant effusion [17]. Furthermore, the numbers of Leu7+ natural killer (NK) cells were higher in both serum and effusions from patients with carcinoma compared to those from tuberculous effusions [18]. These studies demonstrate that immunologically competent activated lymphocytes accumulate at sites of disease activity. 


\section{Macrophages and monocytes}

The circulating monocyte may also be recruited by means of mesothelial cell-derived MCP [6] to the pleural space. Although there is no specific disease associated with macrophage/monocyte predominance, the cells may participate in the pleural reaction of several diseases. In tuberculosis the recruited and activated peripheral blood monocyte plays a critical role in granuloma formation. In asbestosis, mononuclear phagocytes have been shown to release oxygen radicals. For example, macrophages may produce active oxygen radicals during unsuccessful phagocytosis of long asbestos fibres $[19,20]$. In tetracycline pleurodesis, pleural macrophages suppress mesothelial growth and stimulate mesothelial cell collagen production [21]. Finally, macrophages obtained from patients with malignant effusion expressed the human leucocyte antigen (HLA)-DR antigen, released interleukin-1 $\beta$ (IL-1 $\beta$ ) and tumour necrosis factor- $\alpha$ (TNF- $\alpha$ ) and stimulated allogeneic T-lymphocyte proliferation [22]. Pleural macrophages represent the second line of defence against invading organisms or antigens that stimulate their recruitment. In pleural tuberculosis, malignancy and immunological diseases, such as lupus erythematosus, the pleural macrophage represents a critical immunological roadblock to the dissemination of infection and containment of malignant cells.

\section{Mesothelial cells}

Despite a general agreement that pleural inflammation involves the pleural surface cells, few studies address the role and direct participation of mesothelial cells in the pathogenesis of the disease. Several recent investigations have shown, however, that this cell type is metabolically active and possesses the capacity to release various cytokines. For instance, a platelet-derived growth factor (PDGF)-like growth factor has been shown to be present in the supernatant of asbestos-stimulated mesothelial cells [23]. In addition, high level expression of messenger ribonucleic acid (mRNA), protein, and bioactivity for both the A and B isoforms of PDGF have been shown for human and mouse mesothelioma cell lines [23] which may promote autocrine growth of the tumour cells [24]. Moreover, rat visceral mesothelial cells secreted a growth-factor-like activity for fibroblasts following stimulation with tetracyline, but not bleomycin [2, 25]. Furthermore, ANTONy et al. [26] showed that crocidolite asbestos stimulated rabbit pleural mesothelial cells to release a chemotactic peptide for neutrophils that was subsequently identified as the neutrophil-activating cytokine, IL-8 [5]. In vitro studies employing cultured human pleural mesothelial cells have demonstrated that the IL-8 release was associated with avid engulfment of asbestos fibres by the cells and that cytokine release was enhanced in the presence of both IL- $1 \beta$ and TNF- $\alpha$. In addition, preincubation of the cells with the interleukin-1 (IL-1) receptor antagonist (IL-1ra) attenuated asbestos-induced IL-8 secretion, suggesting that mesothelial cells also release IL-1 [6]. Furthermore, human pleural mesothelial cells activated by bacterial endotoxin lipopolysaccharide, IL-1 $\beta$ and TNF- $\alpha$ released MCP-1 and IL-8 [6].
In addition to the release of cytokines, mesothelium has been shown to produce other proteins that may be involved in pleural inflammatory responses. For instance, recent studies suggest that mesothelial cells may produce collagen [21] and nitric oxide (NO) when exposed to cytokines and bacterial products [27]. Confluent layers of rat mesothelial cells generated large amounts of NO when exposed to IL- $1 \beta$, TNF- $\alpha$ and lipopolysaccharide, while interferon- $\gamma$ (IFN- $\gamma$ ) was less effective [28]. Furthermore, mesothelial cells exposed to asbestos fibres produced antioxidant enzymes [29] and showed an increased expression of adhesion molecules on their surface. Finally, transforming growth factor (TGF) and TNF- $\alpha$ induce the elaboration and release of plasminogen activation inhibitor (PAI)-1 and PAI-2 from mesothelial cells $[30,31]$. Taken together, these data strongly suggest that mesothelial cells may actively participate in both immunological and coagulatory processes within the pleural space.

\section{Other cells}

Plasma cells and basophils are only rarely observed in pleural fluid. Although the cells may occasionally be detected in multiple myeloma or leukaemia [32], their diagnostic value is limited. Moreover, neither plasma cells nor basophils appear to play a major role in pleural inflammation.

\section{Immunological processes in pleural diseases}

Stimulation of the mesothelial cells by invading agents, along with infiltration and activation of inflammatory cells culminates in a pleural inflammatory reaction. On the basis of the current knowledge on pleural cell infiltration and mediator release described above, putative immunological mechanisms can be proposed regarding the events that occur in the course of certain diseases involving the pleural space.

\section{Complicated parapneumonic pneumonia and empyema}

Exudates due to parapneumonic pneumonia and empyema are characterized by neutrophilic pleocytosis [1], decreased $\mathrm{pH}$ and increased lactate dehydrogenase (LDH) levels. In addition, when compared to pleural effusions of a different origin, the concentration of platelet-activating factor (PAF) [12] and certain cytokines is elevated. Moreover, in contrast to transudates, exudates due to parapneumonic effusions and empyema show increased procoagulant and depressed fibrolytic activities favouring fibrin deposition in the pleural space [30].

Endotoxin and other bacterial-derived components are likely to represent the principle pathogenetic factors underlying pleural inflammation due to infection. As has been shown for pneumococcal infections [33], bacterial cell wall components bind to leucocytes and possibly mesothelial cells, eliciting the production of IL-1, IL-6, IL-8, and TNF- $\alpha$ [34], as well as PAF [35]. IL8 , PAF, and chemotactic cell wall components cause migration of neutrophils into the pleural cavity via CD18dependent and -independent mechanisms [35], which 
further contribute to the production of inflammatory mediators. Activation of the alternative pathway of the complement cascade by fragments of the bacterial cell wall further amplifies recruitment of leucocytes [33]. Moreover, both cell wall components and mediators may increase the permeability of adjacent capillaries leading to raised fluid accumulation. In addition, bacterial cell wall-derived fragments may also induce expression of tissue factor on both endothelial cells [36] and mesothelial cells [30] that binds to factor VII on the cell surface to initiate the coagulation cascade [33]. As leucocytes begin to counteract bacterial infection, dying bacteria and leucocytes release more bacterial compounds, proteases, proteins and other factors, leading to greater inflammation. However, since bacteria and bacterial degradation products cannot be drained, as in pneumonia, the infection-associated inflammation may prevail and may further increase even under appropriate antibiotic treatment. Thus, early and sufficient drainage of pleural empyema is important in interrupting the vicious cycle and may help prevent the long-term sequelae.

When, at this stage, therapeutic intervention is not initiated, transition to chronic empyema occurs, which involves deposition of fibrin and proliferation of fibroblasts. Continuing fibrosis eventually forms inelastic membranes promoting both lung entrapment and restriction of movement of the chest wall and diaphragm and leading to a shrunken, immobile hemithorax with crowding of the ribs and scoliosis. The important pathogenic link from pleural inflammation to fibroblast proliferation is provided by the release of the PDGF-like growth factor from mesothelial cells [2]. In addition, mesothelial cells, in response to TNF- $\alpha$ and TGF, may also release PAI-1 (or mesocrin) and PAI-2 [30, 31], which promotes fibrin deposition and eventually leads to local organization and multiple pleural space loculations. Drainage of pus containing several proinflammatory mediators and cellular debris removes the inciting agents of inflammation and may lead to resolution of inflammation without fibrosis, and regeneration of the denuded mesothelium.

\section{Tuberculous pleurisy}

Mycobacterium tuberculosis-induced pleural effusion often occurs in conjunction with pulmonary infiltrates typical of post-primary tuberculosis, but may also manifest as a primary feature of the disease [37, 38]. Although bilateral effusions may occur in miliary tuberculosis, unilateral effusions predominate and arise secondarily to rupture of a caseous subpleural focus into the adjacent pleural space [39]. The pleural fluid collects as a result of a delayed hypersensitivity reaction to tuberculous proteins [40]. Lymphocytes are the predominant cell type, amounting to more than $70 \%$ of the total white cell count, and these cells are mainly of the CD4+ phenotype [15, 41, 42]. Although neutrophils can also be found during mycobacterial invasion, their presence is restricted to the early stages of the disease and numbers exceeding $50 \%$ of total white cells in the later stages of the disease may indicate a nontuberculous aetiology.

Invasion of the pleural space by mycobacteria results in a delayed hypersensitivity reaction [39] with sensitization of lymphocytes to purified protein derivative (PPD) [41]. In addition, there is ample evidence that lymphocytes in tuberculous pleurisy are activated and show an enhanced cytotoxic capacity. For instance, CD4+ lymphocytes obtained from tuberculous pleurisy and stimulated in situ [42] or ex vivo [43] with mycobacterial antigens produce significant amounts of IFN- $\gamma$. IFN- $\gamma$ and other cytokines may, in part, be produced by $\gamma$ or $\delta$ T-lymphocytes, which are closely linked to antimycobacterial immunity [44]. In addition, the proliferation rate and cytotoxicity of CD4+ lymphocytes is augmented when compared to cells from autologous peripheral blood and nontuberculous effusions.

The fundamental role of IFN- $\gamma$ in tuberculous pleural effusions is further supported by the demonstration of high IFN- $\gamma$ levels in tuberculous pleural effusion [45-47]. Adenosine deaminase (ADA) and IFN- $\gamma$ concentrations have been demonstrated to be useful in narrowing the diagnosis [47-49] since, in malignant and parapneumonic effusions, empyema and transudates, only low values of this IFN- $\gamma$ can be detected. In addition to IFN- $\gamma$, TNF- $\alpha$, transforming growth factor- $\beta$ (TGF- $\beta$ ), IL-1 $\beta$, IL-2, IL-2 receptor (IL-2) and IL-1Ra have been found to be raised [50-52]. While TNF- $\beta$ and IFN- $\gamma$ may participate in the host immune response caused by mycobacteria and may mediate the clinical manifestation of tuberculous pleuritis, such as fever, exudative pleural effusion, and tissue necrosis [51], TGF- $\beta$ has been reported to be involved in tissue repair processes in the course of tuberculous inflammation [52].

\section{Asbestos-related pleural inflammation}

Asbestos-related pleural disease occurs in a variety of manifestations, ranging from benign pleural effusion, pleural plaques, diffuse pleural thickening, to diffuse malignant mesothelioma. The incidence of these has been steadily increasing over the last $20 \mathrm{yrs}$ and is expected to continue for at least another 20 yrs as a consequence of widespread occupational exposure and the long latency period [53].

Although it has been well established that inhalation of asbestos causes pleural inflammation, the cellular immune reactions underlying the pathogenesis are largely unknown [20]. Recently, it has been shown that asbestos causes prolonged induction of $c$-fos and $c$-jun protooncogene expression in rat pleural mesothelial cells, whereas other mineral fibres that do not give rise to pulmonary disease failed to induce these genes [54]. Persistent induction of the early response gene pathway may lead to chronic cell proliferation and asbestos-induced pleural disease. In addition, persistent production of reactive oxygen radicals by inflammatory cells, such neutrophils or macrophages, undergoing frustrated phagocytosis of asbestos fibres may trigger chronic cell proliferation and inflammation [55]. Both macrophage and mesothelial products (IGF, TGF- $\alpha$, TGF- $\beta$, PDGF, TNF- $\alpha$ ) may promote proliferation of fibroblasts and their matrix products, leading to pleural fibrosis (for review see [56]). In addition, exposure of fibroblasts to asbestos may also result in PDGF release, which may further contribute to fibroblast proliferation and fibrogenesis through an 
autocrine loop [57]. Finally, as has been observed in empyema and pleurodesis, fibrin deposition is likely to occur in asbestos-related pleural disease, promoting fibroblast adherence, proliferation and collagen production [58].

\section{Pleural mesothelioma}

The most serious consequence of asbestos exposure is the development of pleural mesothelioma, although a significant proportion of patients present without any known history of exposure [59]. The strong association between malignant mesothelioma and occupational exposure to asbestos fibres, particularly of the amphibole type [60], but also the zeolite mineral, erionite [61], was clearly established in 1960, and has since been repeatedly confirmed [62]. In spite of substantial efforts, current treatment modalities have proven ineffective, and the median time from diagnosis to death is approximately 9 months. Thus, since refinement of current therapeutic approaches is unlikely to improve prognosis, improved understanding of the basic biology of mesothelioma and the host immune response to the tumour is required to provide a rational platform from which new approaches can be developed [56].

As has been suggested for other asbestos-related diseases (see above), both the induction of early proto-oncogene and growth factor expression, [54] as well as chronic inflammation, may play an important role in the carcinogenesis of mesothelioma. However, as observed in other tumour systems [63], this response may be rendered ineffective by mesothelial-derived products [64]. Several immune-evasive actions of the mesothelioma cell may be operative. Firstly, tumour infiltrating lymphocytes not only show down-regulation of certain surface markers, including CD2 and CD3 [65], but also a reduced mRNA expression for some subunits of the CD3 complex [66]. Secondly, tumour infiltrating macrophages exhibit reduced expression of major histocompatibility complex (MHC) class II and adhesion molecules [65]. Thirdly, mesothelioma cells are capable of both expressing and producing immunosuppressant cytokines, such as TGF- $\beta$, which may mediate some of the inhibitory effects on immune cells mentioned above [67].

Mesothelioma cells may also produce other cytokines relevant to immune reactions of the host. For instance, the majority of mesothelial tumour cell lines secrete IL6 , a pleiotropic cytokine, which may be involved in local thrombocytosis [3]. In addition, IL-6 may mediate systemic clinical features, such as tumour cachexis [64]. Moreover, the expression of GM-CSF and M-CSF by mesothelioma cells has been reported [3], although their relevance in the tumour-associated immune response remains to be elucidated.

\section{Metastatic carcinomatous pleurisy}

The pleura is frequently involved in primary or secondary malignancies, and this involvement sometimes results in the development of an extensive pleural effusion. Adenocarcinoma of the breast and lung is the most common tumour cell type responsible for pleural effu- sions. The pathogenesis of malignant pleurisy is thought to be due to local tumour cell invasion or haematogenous spread. Inflammatory immunological processes may play a role in the homing mechanisms involved in pleural metastasis. As in tuberculous effusions, CD4+ T-lymphocytes are increased in malignant pleurisy when compared to blood [68]. However, lymphocyte activation parameters, such as CD38 and HLA-DR expression were low when compared to other pleural diseases suggesting that CD4+ cells may not play a dominant role in the process of metastasis.

In contrast to lymphocytes, there is some evidence that macrophage activation may occur in malignant effusions. A recent study demonstrated that pleural macrophages from patients with malignancy expressed the HLA-DR antigen and spontaneously produced IL-1 $\beta$ and TNF- $\alpha$ [22]. In addition, these cells also stimulated allogeneic T-lymphocyte proliferation, possibly representing accessory cells. Indeed, dendritic cells with a potent accessory activity have recently been identified in human exudative malignant pleural effusion [69]. However, it remains to be elucidated, whether these cells are involved in tumour-associated inflammatory reactions and contribute to the development of the pleural effusion.

\section{Pleurodesis}

A number of drugs and physical agents, such as tetracycline, minocycline, Corynebacterium parvum, talc, bleomycin, nitrogen mustard, doxorubicin, quinacrine, and radioactive colloid gold, have been employed in order to decrease or prevent fluid accumulation in the pleural cavity (for review see [71, 72]). Although the mechanisms underlying drug-induced pleural symphysis are not well understood and may differ depending on the sclerosing agent used, increasing evidence suggests that an inflammatory reaction may play an important role.

Instillation of a sclerosing substance, such as tetracyline, causes injury to mesothelial cells ranging from cuboidal transition to total cell desquamation [72]. In addition, a dramatic increase in pleural neutrophil counts is being observed [73]. Since tetracycline itself has no direct tumouricidal effect, these phenomena are believed to be mediated through local stimulation of the mesothelial cell. Indeed, intrapleural administration of tetracycline results in significantly raised levels of IL-6, IL-8 and TNF- $\alpha$. Furthermore, quinacrine instillation also causes the production of both IL- $1 \beta$ and TNF- $\alpha$. These cytokines may be released from pleural macrophages and mesothelial cells upon exposure to tetracyline or other sclerosants [2].

While TNF- $\alpha$ may exert some antitumour activity, the chemotactic IL-8 and possibly C5a or $\mathrm{LTB}_{4}$ [74] may be responsible for attracting neutrophils. Upon exposure to IL-6, IL-8, and TNF- $\alpha$, intrapleural neutrophils may, in turn, release proteolytic enzymes and toxic oxygen radicals, thereby damaging the mesothelial cell lining of the pleura and inducing pleural repair mechanisms. Finally, since intense proliferation of fibroblasts can be seen on the pleural surface within 3 days of pleurodesis [72], pleural fibrosis may develop as a consequence of these processes and a mesothelial-derived 
growth-factor-like activity [2], which revealed several similarities to platelet-derived growth factor (PDGF).

The inflammatory processes following instillation of a sclerosant are accompanied by fibrin deposition on both the visceral and parietal pleural surfaces [75]. Intrapleural administration of a sclerosing agent induces a marked increase in thrombin activity and fibrinopeptide A (FPA), while the fibrolytic activity declines within a period of $24 \mathrm{~h}$ [75]. Fibrin forms a latticework that promotes pleural adhesion. Fibrin, fibrinogen, and their degradation peptides induce fibroblast adherence, proliferation, and collagen production $[58,76]$. In addition, these factors may directly alter vascular permeability [77] and serve as chemotaxins [78] for fibroblasts. Consequently, it is thought that a fibrin lattice forms between visceral and parietal pleural surfaces and provides a template for fibroblast growth and proliferation. The significance of pleural coagulation for pleural symphysis has been supported by a recent study demonstrating that successful pleurodesis is strongly related to persistently raised fibrinolytic activity [75].

\section{Summary}

Cellular immune responses appear to be the predominant mechanisms involved in the pathogenesis of most inflammatory pleural effusions. Recent advances in basic research have begun to extend our knowledge and understanding of the immunological mechanisms underlying pleural inflammation.

Clearly, understanding the pleural inflammatory mechanisms has direct clinical implications, although many aspects relating to pleural inflammation and disease progression or resolution remain only partially understood. For instance, pleural repair processes may either proceed to repair with fibrosis or repair without fibrosis and re-establishment of the mesothelial monolayer [2]. However, the factors determining the transition from pleural inflammation to either fibrosis or resolution remain to be defined. In addition, as emphasized above, empyema tends to form loculations which hinder complete drainage and provide the basis for chronic pleural infection. Chronic inflammation promotes formation of an inelastic membrane around the lung ("pleural peel") leading to lung entrapment as well as fibrothorax and, consequently, to an impaired respiratory function. Furthermore, effective pleurodesis appears to depend on the extent of the artificially induced (inflicted) pleural inflammation and mesothelial injury, but both the inflammatory cells and mediators involved need further definition. Moreover, the inflammatory response may, most likely, vary according to the underlying cause of pleural inflammation, the balance between coagulation and fibrinolysis, and the sclerosant employed. In pneumothorax and haemothorax, both the cause and the role of infiltrating eosinophils is unknown. Finally, current evidence suggests that a unique cytokine profile is produced by mesothelioma cells through which the tumour cells evade host immune defence [24].

As we begin to learn more about the mechanisms involved in the pathogenesis of pleural inflammation, it may be possible to inhibit or redirect immunological processes in order to prevent chronic inflammation, scarring, pleural peel formation, lung entrapment, and malignant transformation. Understanding these processes and the sequence of events leading to pleural loculation, pleural adhesion or repair will provide the basis for early therapeutic intervention and reduce pleuralassociated morbidity.

\section{References}

1. Light RW. In: Pleural diseases. Lea \& Febiger, Philadelphia, 1990.

2. Antony VB, Rothfuss KJ, Godbey SW, Sparks JA, Hott JW. Mechanism of tertacycline-hydrochloride-induced pleurodesis. Tertacycline-hydrochloride-stimulated mesothelial cells produce a growth-factor like activity for fibroblasts. Am Rev Respir Dis 1992; 146: 1009-1013.

3. Schmitter D, Lauber B, Fagg B, Stahel RA. Haemopoietic growth factors secreted by seven human pleural mesothelioma cell lines: interleukin-6 production as a common feature. Int J Cancer 1992; 51: 296-301.

4. Antony VB, Godbey SW, Kunkel SL, et al. Recruitment of inflammatory cells to the pleura space: Chemotactic cytokines IL-8, and monocyte chemotactic peptide- 1 in human pleural fluids. J Immunol 1993; 151: 7216-7223.

5. Boylan AM, Ruegg C, Kim KJ, et al. Evidence of a role for mesothelial cell-derived interleukin- 8 in the pathogenesis of asbestos-induced pleurisy in rabbits. $J$ Clin Invest 1992; 89: 1257-1267.

6. Antony VB, Godbey SW, Kunkel SL, et al. Pleural mesothelial cell expression of C-C (monocyte chemotactic peptide [MCP-1]) and $\mathrm{C}-\mathrm{X}-\mathrm{C}$ (Interleukin-8 [IL8]) chemokine. Am J Respir Cell Mol Biol 1995; 12: 581-588.

7. Padock FK. The diagnostic significance of serous fluids in disease. N Engl J Med 1940; 223: 1010-1014.

8. Hofstetter M, Luttmann W, Kortsik C, Virchow JC jr, Matthys H, Kroegel C. Discrepancy between eosinophil counts and eosinophil cationic protein (ECP) in malignant pleural effusion. Eur Respir J 1995; 8: 205s.

9. Spriggs AI. Pleural eosinophilia due to pneumothorax. Acta Cytol (Baltimore) 1979; 23: 425.

10. Johnson RJ, Johnson JR. Paragonimiasis in Indochinese refugees: roentgenographic findings with clinical correlations. Am Rev Respir Dis 1983; 128: 534-538.

11. Kroegel C, Warner JA, Matthys H, Virchow JC Jr. Pulmonary immune cells in health and disease. The eosinophil leukocyte. Part II. Eur Respir J 1994; 7: $743-$ 760.

12. Oda M, Satouchi K, Ikeda I, Sakakura M, Yasunga K, Saito K. The presence of platelet-activating factor associated with eosinophil and/or neutrophil accumulation in the pleural fluids. Am Rev Respir Dis 1990; 141: 1469-1473.

13. Yam LT. Diagnostic significance of lymphocytes in pleural effusions. Ann Intern Med 1967; 66: 972-982.

14. Domagala W, Emeson EE, Koss LG. T and B lymphocyte enumeration in the diagnosis of lymphoyte-rich pleural fluids. Acta Cytol 1981; 25: 108-110.

15. Bergroth V, Konttinen YT, Nordstrom D, Petterson T, Tolvanen E. Lymphocyte subpopulations, activation phenotypes, and spontaneous proliferation in tuberculous pleural effusions. Chest 1987; 91: 338-341.

16. Baganha MF, Pego A, Lima MA, Gaspar EV, Pharm B, Cordeiro AR. Serum and pleural adenosine deaminase: correlation with lymphocytic populations. Chest 1990; 97: 605-610. 
17. Takahashi K, Sone S, Kimura S, Ogura T, Monden Y. Phenotypes and lymphokine-activated killer activity of pleural cavity lymphocytes of lung cancer patients without malignant effusion. Chest 1993; 103: 1732-1738.

18. Lucivero G, Pierucci G, Bonomo L. Lymphocyte subsets in peripheral blood and pleural fluid. Eur Respir $J$ 1988; 1: 337-340.

19. Hansen K, Mossman BT. Generation of superoxide from alveolar macrophages exposed to asbestiform fibers and nonfibrous particulates. Cancer Res 1987; 47: 1681-1686.

20. Donaldson K, Cullen RT. Chemiluminescence of asbestos-activated macrophages. Br J Exp Pathol 1984; 65: 81-90.

21. Baumann M, Heinrich K, Sahn SA, Strange C. Pleural macrophages differentially alter mesothelial cell growth and collagen production. Inflammation 1993; 17: 1-12.

22. Gjomarkaj M, Pace E, Melis M, Spatafora M, Toews GB. Mononuclear cells in exudative malignant pleural effusions. Characterization of pleural phagocytic cells. Chest 1994; 106: 1042-1049.

23. Christmas TI, Mutsaers SE, Manning LS, Davis MR, Robinson BWS. Platelet-growth factor as an autocrine factor in murine malignant mesothelioma. Eur Respir Rev 1993; 3: 192-194.

24. Fitzpatrick DR, Peroni DJ, Bielefeld-Ohmann H. The role of growth factors and cytokines in the tumorigenesis and immunobiology of malignant mesothelioma. Am J Respir Cell Biol 1995; 12: 455-460.

25. Jonjic N, Peri G, Bernasconi S, et al. Expression of adhesion molecules and chemotactic cytokines in cultured human mesothelial cells. J Exp Med 1992; 176: $1165-1174$.

26. Antony VB, Hadley KJ, Sahn SA: Mechanism of pleural fibrosis in empyema: pleural macrophage mediated inhibition of fibroblast proliferation. Chest 1989; 95: S230-S231.

27. Tracey WR, Nakane M, Kuk J, et al. The nitric oxide synthetase inhibitor: L-NG-monomethylarginine, reduces carrageenan-induced pleurisy in the rat. J Pharmacol Exp Ther 1995; 273: 1295-1299.

28. Owens MW, Grisham MB. Nitric oxide synthesis by rat pleural mesothelial cells: induction by cytokines and lipopolysaccharide. Am J Physiol 1993; 265: L110-L116.

29. Janssen YMW, Marsh JP, Absher MP, et al. Oxidant stress response in human pleural mesothelial cells exposed to asbestos. Am J Respir Crit Care Med 1994; 149: 795-802.

30. Idell S, Zwieb C, Kumar A, Koenig KB, Johnson AR. Pathways of fibrin turnover of human pleural mesothelial cells in vitro. Am J Respir Cell Mol Biol 1992; 7: 414-426.

31. Philip-Joet F, Alessi MC, Philip-Joet C, et al. Fibrinolytic and inflammatory processes in pleural effusions. Eur Respir J 1995; 8: 1352-1356.

32. Spriggs AI, Boddington MM. The cytology of effusions. The Cytology of Effusions, 2nd Edition, Grune \& Stratton, New York, 1968.

33. Tuomanen EI, Austrain R, Msure HR. Pathogenesis of pneumococcal infection. $N$ Engl J Med 1995; 332: $1280-1284$.

34. Heumann D, Barras C, Severin A, Glauser MP, Tomasz A. Gram-positive cell walls stimulate synthesis of tumor necrosis factor alpha and interleukin- 6 by human monocytes. Infect Immun 1994; 62: 2715-2721.

35. Cabellos C, MacIntyre DE, Forrest M, Burroughs M, Prasad S, Tuomanen E. Differing roles for platelet acti- vating factor during inflammation of the lung and subarachnoid space: the special case of Streptococcus pneumoniae. J Clin Invest 1992; 90: 612-618.

36. Geelen S, Bhattacharyya C, Tuomanen E. Induction of procoagulant activity on human endothelial cells by Streptococcus pneumoniae. Infect Immun 1992; 60: 4179-4183.

37. Seibert AF, Haynes J, Middleton R, Bass JB. Tuberculous pleural effusion: twenty-year experience. Chest 1991: 99: 883-886.

38. Metha JB, Dutt A, Harvill L, Mathews KM. Epidemiology of extrapulmonary tuberculosis. Chest 1991; 99: 1134-1138.

39. Stead WW, Eichenholz A, Strauss HK. Operative and pathologic findings in twenty-four patients with syndrome of idiopathic pleurisy with effusion, presumably tuberculous. Am Rev Respir Dis 1955; 71: 473-479.

40. Allen JC, Apicella MA. Experimental pleural effusions as a manifestation of delayed hypersensitivity to tuberculin PPD. J Immunol 1968; 101: 481-487.

41. Fujiwara H, Tsuyuguchi I. Frequency of tuberculinreactive T-lymphocytes in pleural fluid and blood from patients with tuberculous pleurisy. Chest 1986; 89: 530-537.

42. Ribera E, Ocana I, Matinez-Vazquez JM, Rossell M, Espanol T, Ruibal A. High levels of interferon gamma in tuberculous pleural effusion. Chest 1988; 93: 308311.

43. Ribera E, Esponol T, Matinez-Vazquez JM, Ocana I, Encabo G. Lymphocyte proliferation and gamma-interferon production after in vitro stimulation with PPD: differences between tuberculous and non-tuberculous pleurisy in patients with positive tuberculin skin test. Chest 1990; 97: 1381-1385.

44. Barnes PF, Grisso CL, Abrams JS, Band H, Rea TH, Modlin RL. Gamma delta T-lymphocytes in human tuberculosis. J Infect Dis 1992; 165: 506-512.

45. Valdes L, Jose ES, Alvarez D, et al. Diagnosis of tuberculous pleurisy using the biologic parameters adenosine deaminase, lysozyme, and interferon gamma. Chest 1993; 103: 458-465.

46. Villena V, Lopez-Encuentra A, Echave-Sustaeta J, et al. Interferon- $\gamma$ in 388 immunocompromised and immunocompetent patients for diagnosing pleural tuberculosis. Eur Respir J 1996; 9: 2635-2639.

47. Söderblom T, Nyberg P, Teppo AM, Klockars M, Riska $\mathrm{H}$, Pettersson T. Pleural fluid interferon- $\gamma$ and tumor necrosis factor- $\alpha$ in tuberculous and rheumatoid pleurisy. Eur Respir J 1996; 9: 1652-1655.

48. Valdes L, San Jose E, Alvarez D, Valle JM. Adenosine deaminase (ADA) isoenzyme analysis in pleural effusions: diagnostic role, and relevance to the origin of increased ADA in tuberculous pleurisy. Eur Respir $J$ 1996; 9: 747-751.

49. Gakis C. Adenosine deaminase (ADA) isoenzymes ADA1 and ADA2: diagnostic and biological role. Eur Respir $J$ 1996; 9: 632-633.

50. Barnes PF, Fong SJ, Brennan PJ, Twonmey PE, Mazumder A, Modlin RL. Local production of tumor necrosis factor and IFN-gamma in tuberculous pleuritis. J Immunol 1985; 145: 149-154.

51. Maeda J, Ueki N, Ohkawa T, et al. Local production and localization of transforming growth factor-beta in tuberculous pleurisy. Clin Exp Immunol 1993; 92: 32-38.

52. Yanagawa H, Yano S, Haku T, Ohmoto Y, Sone S. Interleukin-1 receptor antagonist in pleural effusion due 
to inflammatory and malignant lung disease. Eur Respir J 1996; 9: 1211-1216.

53. Peto J, Hodgson JT, Matthews FE, Jones JR. Continuing increase in mesothelioma mortality in Brirain. Lancet 1995; 345: 535-539.

54. Heintz, NH, Janssen YMW, Mossman BT. Persistent induction of c-fos and c-jun expression by asbestos. Proc Natl Acad Sci 1993; 90: 3299-3303.

55. Marsh JP, Mossman BT. Role of asbestos and active oxygen species in activation and expression of ornithine decarboxylase in hamster tracheal epithelial cells. Cancer Res 1991; 51: 167-173.

56. Upham JW, Garlepp MJ, Musk AW, Robinson BWS. Malignant mesothelioma: new insights into tumour biology and immunology as a basis for new treatment approaches. Thorax 1995; 50: 887-893.

57. Lasky JA, Coin PG, Lindroos PM, Ostrowski LE, Brody AR, Bonner JC. Chrysotile asbestos stimulates plateletderived growth factor-AA production by rat lung fibroblasts in vitro: evidence for an autocrine loop. Am J Respir Cell Mol Biol 1995; 12: 162-170.

58. Senior RM, Skodgen WF, Griffen GL, Wilner GD. Effects of fibrinogen derivatives upon the inflammatory response. J Clin Invest 1986; 77: 1014-1019.

59. Garlepp MJ, Leong CC. Biological and immunological aspects of malignant mesothelioma. Eur Respir J 1995; 8: 643-650.

60. Mossman BT, Bignon J, Corn M, Seaton A, Gee JBL. Asbestos: scientific developments and implications for public policy. Science 1990; 247: 294-301.

61. Artvinli M, Baris YI. Malignant mesothelioma in a small village in the Anatolien region in Turkey: an epidemiological study. J Natl Cancer Inst 1979; 63: 17-22.

62. Wagner JC. The discovery of the association between blue asbestos and mesotheliomas and the aftermath. $J$ Ind Med 1991; 48: 399-403.

63. Tada T, Ohzeki S, Utsumi K, Takiiuchi H, Muramatsu M, Shimizu J. Transforming growth factor-beta induced inhibition of T-cell function. Susceptibility differences in T-cells of various phenotypes and functions and its relevance to immunosuppression in the tumour-bearing state. J Immunol 1991; 146: 1007-1082.

64. Bielefeld-Ohmann H, Fitzpatric DR, Marzo AL, Jarnicki AG, Musk AW, Robinson BWS. Potential for interferon-alpha-based therapy in mesothelioma: assessment in a murine model. J Interferon Cytokine Res 1995; 15: 213-223.

65. Bielefeld-Ohmann H, Fitzpatric DR, Marzo AL, et al. Patho- and immunobiology of malignant mesothelioma: characterisation of tumour infiltrating leukocytes and cytokine production in a murine model. Cancer Immunol Immunother 1994; 39: 347-359.
66. Jarnicki AG, Fitzpatric DR, Marzo AL, Robinson BWS, Bielefeld-Ohmann H. Surface antigen and cytokine profile of tumor infiltrating lymphocytes (TIL) in malignant mesothelioma. J Leuk Biol 1993; 54 (Suppl): 90-95.

67. Fitzpatrick DR, Bielefeld-Ohmann H, Himbeck RP, Jarnicki AG, Marzo AL, Robinson BWS. Transforming growth factor-beta: antisense RNA-mediated inhibition affects anchorage-independent growth, tumorigenicity and tumour-infiltrating T-cells in malignant mesothelioma. Growth Factors 1994; 11: 29-44.

68. Guzman J, Bross KJ, Costabel U. Malignant pleural effusions due to small cell carcinoma of the lung. An immunohistochemical cell-surface analysis of lymphocytes and tumor cells. Acta Cytol 1990; 34; 497501.

69. Gjomarkaj M, Pace E, Melis M, Spatafora M, D'Amico D, Toews GB. Dendritic cells with a potent accessory activity are present in human exudative malignant pleural effusions. Eur Respir J 1997; 10: 592-597.

70. Walker-Renard PB, Vaughan LM, Sahn SA. Chemical pleurodesis for malignant pleural effusions. Ann Intern Med 1994; 120: 56-64.

71. Rodriguez-Panadero F, Antony VB. Pleurodesis: state of the art. Eur Respir J 1997; 10: 1648-1654.

72. Strange C, Tomlinson JR, Wilson C, Harley R, Miller KS, Sahn SA. The history of experimental pleural injury with tetracycline, empyema, and carrageenan. Exp Mol Pathol 1989; 51: 205-219.

73. Rossi GA, Sacco O, Balzano E. Cell mediated immunity in malignant pleural effusions. Am Rev Respir Dis 1984; 129: 8A.

74. Kato H, Yamamura Y, Kin R, et al. Treatment of malignant ascitis and pleurisy by a streptococcal preparation OK-432 with fresh frozen plasma: a mechanism of polymorphonuclear leukocyte (PMN) accumulation. Intern J Immunopharmacol 1989; 11: 117-128.

75. Rodriquez-Panadero F, Segado A, Juan LM, Garcia IT, Castillo J. Failure of talc pleurodesis is associated with increased pleural fibrinolysis. Am J Respir Crit Care Med 1995; 151: 785-790.

76. Gray AJ, Bishop JE, Reeves JT, Mecham RP, Laurent GF. Partially degraded Fibrin(ogen) stimulates proliferation in vitro. Am J Respir Cell Mol Biol 1995; 12: 684-690.

77. Dang CV, Bell WR, Kaiser D, Wong A. Disorganization of cultured vascular endothelial cell monolayers by fibrinogen fragment D. Science 1985; 227: 1487-1490.

78. Sueshi KS, Nanno S, Tanaka K. Permeability enhancing and chemotactic activities of lower molecular weight degradation products of human fibrinogen. Thromb Haemost 1981; 45: 90-94. 